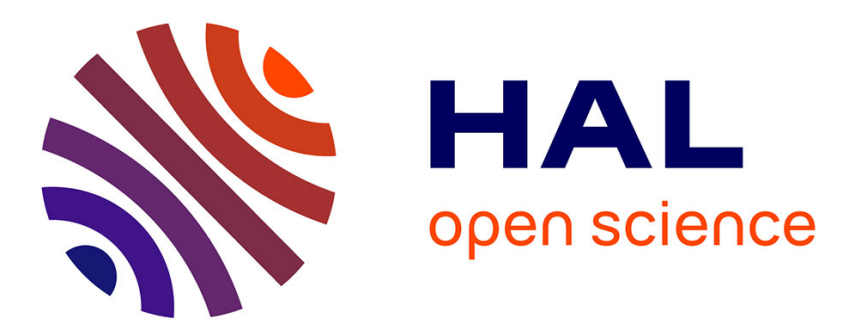

\title{
Modeling of the Heterogeneous Damage Evolution at the Granular Scale in Polycrystals under Complex Cyclic Loadings
}

\author{
Akrum Abdul-Latif, M. Chadli
}

\section{- To cite this version:}

Akrum Abdul-Latif, M. Chadli. Modeling of the Heterogeneous Damage Evolution at the Granular Scale in Polycrystals under Complex Cyclic Loadings. International Journal of Damage Mechanics, 2007, 16 (2), pp.133-158. 10.1177/1056789506064937 . hal-00571154

\section{HAL Id: hal-00571154 \\ https://hal.science/hal-00571154}

Submitted on 1 Mar 2011

HAL is a multi-disciplinary open access archive for the deposit and dissemination of scientific research documents, whether they are published or not. The documents may come from teaching and research institutions in France or abroad, or from public or private research centers.
L'archive ouverte pluridisciplinaire HAL, est destinée au dépôt et à la diffusion de documents scientifiques de niveau recherche, publiés ou non, émanant des établissements d'enseignement et de recherche français ou étrangers, des laboratoires publics ou privés. 


\title{
Modeling of the Heterogeneous Damage Evolution at the Granular Scale in Polycrystals under Complex Cyclic Loadings
}

\author{
A. Abdul-LatiF* AND M. Chadli \\ L3M, IUT de Tremblay, 93290 Tremblay-en-France, France
}

\begin{abstract}
In this study, a new extension of a micromechanical approach proposed recently by the authors is developed to predict the damaged behavior of polycrystals under various multiaxial cyclic loading paths. The model is expressed in the time dependent plasticity for a small strain assumption. With the framework of the continuum damage mechanics (CDM), it is assumed that a scalar damage variable $\left(d^{\mathrm{g}}\right)$ initiates and then evolves at the granular level where the phenomenon of the localized plastic deformation occurs. The driving force of this variable depends on the granular elastic and inelastic energies. This variable can globally describe the microcrack and/or microcavity. The developed aspects involve the development of a new mesodamage initiation criterion, which depends not only on the accumulated granular plastic strain but also on the applied loading path complexity; another new criterion related to macroscopic damage initiation is also developed through the probabilistic approach of Weibull. This gives finally a mixed approach (micromechanical-probabilistic). An experimental program is proposed with the purpose of studying the cyclic behavior of the aluminum alloy 2024 . Hence, a series of cyclic uniaxial and biaxial tests is performed up to final fracture of the specimens. After the model parameters identification, the model is examined to demonstrate that it is powerful in reproducing the low-cycle fatigue behavior of the employed alloy. Moreover, an application of the model under various cyclic loading types is qualitatively conducted showing the model's ability in describing the principal phenomena observed, especially, in multiaxial plastic fatigue.
\end{abstract}

KEY WORDS: micromechanical model, mesodamage, plastic fatigue, polycrystals, mesodamage initiation criterion, macroscopic damage initiation criterion, complex cyclic loading. *Author to whom correspondence should be addressed. E-mail: aabdul@iu2t.univ-paris8.fr
Figure 3 appears in color online: http://ijd.sagepub.com

International Journal of DAMAge Mechanics, Vol. 16-April 2007 


\section{INTRODUCTION}

$\mathbf{I}$ $\mathrm{N}$ RECENT YEARS, there has been a substantial development of the so-called 'micromechanical modeling' in which the inelastic behavior is represented based on the inelastic slip and hardening along preferred slip planes. Several of these models have almost attained a high level of performance (Hutchinson, 1976; Asaro, 1983; Nemat-Nasser and Obata, 1986; Molinari et al., 1987, 1997; Dingli et al., 2000; Abdul-Latif et al., 2002a and many others). One of the key ingredients for the inelastic modeling is the self-consistent approach. Hence, research efforts developed since the model of Sachs (1928) and Taylor (1938) became a topic of great interest in modeling the overall stress-strain behavior of polycrystals. The elegance of the solutions makes these approaches appealing due to the little required assumptions based on some physical considerations. Moreover, this leads appropriately to predict a host of inelastic behaviors of polycrystalline metals under uniaxial and multiaxial loading paths.

The experimental observations, related to the low-cycle fatigue for FCC polycrystals like the Waspaloy (see, Ferney, 1994; Abdul-Latif et al., 1999) and austenitic stainless steel, demonstrate that microcracks initiate and orient along the slip planes (for example, Heino and Karlsson, 2001).

Regarding the low-cycle fatigue crack nucleation modeling, the selfconsistent approach has not received enough attention from researchers till date and is still in its immaturity. However, some attempts have been made, using the above-mentioned approach in characterizing the stress, strain, and damage responses for polycrystals subjected to different cyclic loading paths (simple and complex) using continuum damage mechanics (CDM) (Abdul-Latif and Saanouni, 1994, 1996, 1997; Abdul-Latif et al., 1999, 2002b; Abdul-Latif, 1999; Saanouni and Abdul-Latif, 1996). The microcrack initiation criterion is based on the accumulated slip on the crystallographic slip system. Thus, the number of needed cycles to initiate a microcrack for a given loading amplitude can easily be estimated. Despite adopting the isotropic damage concept, the model describes the damaged behavior emphasizing the advantages to predict correctly the fatigue life related to the complexity of the loading path, i.e., the greater the complexity of the loading path, the greater the additional hardening; the shorter the fatigue life becomes consequently. However, the aboveproposed model reveals some restrictions because it can only describe the damaged behavior of those materials like the Waspaloy (Abdul-Latif et al., 1999) and nickel-base alloy C263 (Manonukul and Dunne, 2004) in which the damage initiation takes place at the slip system level. Hence, this assumption makes this approach quite limited in its application for other metals. However, in the case of aluminum alloy 2024 (Al-2024), as an 
example, the damage takes the form of microcavity at the granular level (Ferney, 1994). It is obvious that the above model cannot describe such a type of granular damaging. As a result, it has been recently demonstrated (Chadli and Abdul-Latif, 2005) that the damage is modeled at the mesoscale by means of the rational framework of the CDM in order to increase the model applicability in reproducing the damaged behavior in other materials.

The recent achievement in Chadli and Abdul-Latif (2005) provides a useful tool for life evaluation of those structural components subjected to numerous complex cyclic loading conditions. Indeed, this model has been expressed in the time dependent plasticity for a small strain assumption to predict the plastic fatigue for FCC metallic polycrystals under multiaxial loading paths. As mentioned above, the main goal of their work was to generalize the model already developed by the author in describing the cyclic stress-strain evolution during plastic fatigue. Accordingly, it has been assumed that a damage variable initiates and then evolves at the granular level. The driving force of this variable depends not only on the inelastic energy as in Abdul-Latif and Saanouni (1994) but also on the elastic granular one. However, two theoretical limitations can be captured; the first one concerns the predicted difference in fatigue lives for a given polycrystal under several cyclic loading situations having the same equivalent strain. The recorded predictions did not agree with the experimental observations. As a typical example, the difference in predicted fatigue lives in tensioncompression and in tension-torsion with $90^{\circ}$ out-of-phase angle is almost close to 25\% (Chadli and Abdul-Latif, 2005). Nevertheless, experimentally it is more than $600 \%$ in the Waspaloy case (Abdul-Latif et al., 1999). The second limitation relates to the development of a suitable overall damage initiation criterion. In order to overcome such a theoretical restriction, a definition of a completely damaged polycrystal becomes indispensable. The complexity of this point is noticeable, particularly when a micromechanical approach is used for modeling the damage. Actually, the fundamental question concerns the definition of an appropriate damage condition after which a polycrystal (aggregate) can be considered as totally damaged. In other words, what is the required number of grains at the base of which one can consider that a polycrystal is thoroughly damaged? This leads, in reality, to propose a macroscopic damage initiation criterion, since it is not logical and acceptable to damage all the grains in the polycrystal with the aim of determining its fatigue life.

In the light of the above theoretical restrictions, a new fatigue mesodamage initiation criterion is therefore proposed which represents a crucial step allowing the characterization of fatigue damage at the mesoscale and the corresponding evolution in polycrystalline metallic materials. 
Repeating several fatigue tests under the same experimental conditions for a given material leads undoubtedly to different fatigue lives. These lives follow in general a probability law. In order to model a totally damaged polycrystal, resorting to a probability law represents an accurate way justified by the experimental results. Consequently, it is assumed that the fatigue lives follow the Weibull's law through which it is assumed that a polycrystal can be damaged, when its overall damaged energy attains a certain value. The totally damaged polycrystal condition takes place when the probability is almost equal to one. Finally, it is obviously noticed that this newly developed approach can be defined as a mixed approach, i.e., a determinist part (together with the mesodamage) and a probabilistic one representing exclusively the macroscopic damage initiation criterion.

The present study consists of two essential parts, the first deals with the modeling aspects, i.e., presentation of the proposed self-consistent model coupled with damage. After the identification of the material constants for Al-2024, the second part investigates the model capability to reproduce the plastic fatigue behavior of this alloy under different cyclic loadings. Besides, an application of the model is qualitatively conducted under various cyclic loading conditions showing the model ability in describing the principal phenomena observed, especially, under multiaxial plastic fatigue.

\section{MICROMECHANICAL MODELING}

Before presenting the model formulation, the adopted hypothesis must be pointed out. Within the framework of small strain assumption, the elastic anisotropy of the grain and grain rotation will be neglected for simplicity.

$$
\underline{\varepsilon}^{\mathrm{g}}=\underline{\varepsilon}_{\mathrm{el}}^{\mathrm{g}}+\underline{\varepsilon}_{\mathrm{in}}^{\mathrm{g}}
$$

In this scheme, the elastic behavior, which is defined at the granular level, is assumed to be isotropic, uniform, and compressible as in Abdul-Latif et al. (2002). Its heterogeneous distribution from grain to grain within a polycrystalline aggregate is taken into account. Likewise, the heterogeneous inelastic deformation is determined using the slip theory. Expressed in the framework of the self-consistent approach of time dependent plasticity, a micromechanical model of the early fatigue damage initiation is developed here based on a recent proposed model (Chadli and Abdul-Latif, 2005). This model assumes that the mesodamage scalar variable $\left(d^{\mathrm{g}}\right)$ evolves in a bilateral manner when the accumulated granular inelastic strain reaches a certain value (threshold). Its rate is supposed to be principally governed by the total granular energy. It is intriguing to note that all kinds of damage, which take place at those levels, lower than the mesoscale (i.e., dislocations, 
lattice defects, etc.) are globally modeled at this level neglecting the grain boundaries damage. Two new damage initiation criteria at the meso- and macro-scales are developed so as to describe the cyclic stress-strain evolution up to final damaging of polycrystals.

In this approach, three different levels, namely macroscopic (aggregate of grains), mesoscopic (granular), and microscopic (crystallographic slip system 'ss') are used. The index $s \in\{1,2,3, \ldots, n\}$ is associated with the slip system rank with $n$ being the maximum number of octahedral systems in the grain ( $n=12$ for FCC materials). The index $g \in\left\{1,2,3, \ldots, N_{\mathrm{g}}\right\}$ describes the grain rank with $N_{\mathrm{g}}$ being the maximum number of grains contained in the aggregate.

\section{Effective State Variables}

By means of the framework of CDM, the concept of the effective state variables is adopted based on the equivalence of the free energy configuration. Being initiated and then evolving at the granular level, the internal state damage variable $\left(d^{\mathrm{g}}\right)$ is introduced and its associated thermodynamic force is $Y^{\mathrm{g}}$. This force can be decomposed into elastic and inelastic parts. Moreover, the granular elastic tensor $\underline{\varepsilon}_{\mathrm{el}}^{\mathrm{g}}$ is considered as an internal variable associated with the internal granular stress tensor $\underline{\sigma}^{\mathrm{g}}$.

The effective state variables are defined by using the hypothesis of energy equivalence introduced in (Cordebois and Sidoroff, 1979; Saanouni et al., 1994). At the mesoscopic level, the effective state variables are defined as:

$$
\underline{\tilde{\sigma}}^{\mathrm{g}}=\frac{\underline{\sigma}^{\mathrm{g}}}{\sqrt{1-d^{\mathrm{g}}}}, \quad \underline{\tilde{\varepsilon}}_{\mathrm{el}}^{\mathrm{g}}=\underline{\varepsilon}_{\mathrm{el}}^{\mathrm{g}} \sqrt{1-d^{\mathrm{g}}}
$$

At the ss level, it is assumed that all the slip systems (each one defined by means of a couple of internal state variables $\left(q^{\mathrm{s}}, R^{\mathrm{s}}\right)$ to describe the isotropic hardening phenomenon at a grain) are similarly influenced by the mesodamage variable. This assumption is based on the fact that when a grain is completely damaged, it cannot support henceforth any load. With this damage configuration, it is logical to admit that all the slip systems, within such a grain, undergo a discharge mechanism when the grain is totally damaged. Thus, the effective state variables of the isotropic hardening can be deduced as :

$$
\tilde{R}^{\mathrm{s}}=\frac{R^{\mathrm{s}}}{\sqrt{1-d^{\mathrm{g}}}}, \quad \tilde{q}^{\mathrm{s}}=q^{\mathrm{s}} \sqrt{1-d^{\mathrm{g}}}
$$


From the physical viewpoint, the fatigue damage initiation (microcrack and/or microcavity) represents an important stage in fatigue life. The high complexity of the micromechanisms of this stage is related to its local character governed by the microstructure. As a result, it is supposed that the damage occurs at a grain where the plastic deformation is highly localized. So, for each grain, when the latter attains its critical value, the granular damage initiates $\left(d^{\mathrm{g}}>0\right)$. The final granular damage takes place when $d^{\mathrm{g}}=d_{\mathrm{cr}}^{\mathrm{g}}$, i.e., $0 \leq d^{\mathrm{g}} \leq d_{\mathrm{cr}}^{\mathrm{g}} \leq 1$.

It is obvious that the main goal of the used approach is to deduce the overall response of the polycrystal from the well-known properties of the grains and the interaction relation of each grain with its environment. As an appropriate tool, the self-consistent approach is used in order to represent the grain-to-grain interaction. It is supposed that when the macroscopic stress tensor $\underline{\Sigma}$ is applied to a polycrystal, the granular stress tensor $\underline{\sigma}^{\mathrm{g}}$ is then determined. The self-consistent approach of Berveiller-Zaoui (1979) modified by Pilvin (1990) is used:

$$
\underline{\sigma}^{\mathrm{g}}=\underline{\Sigma}+C^{\mathrm{g}}\left\{\sum_{h=1}^{N_{\mathrm{g}}} v^{\mathrm{h}} \underline{\beta}^{\mathrm{h}}-\underline{\beta}^{\mathrm{g}}\right\}
$$

where $\beta^{\mathrm{g}}$ and $C^{\mathrm{g}}$ are the intergranular kinematic hardening and its modulus, respectively. $v^{\mathrm{h}}$ is the volume fraction of the same oriented grains.

The resolved shear stress $\left(\tau^{\mathrm{s}}\right)$ can be obtained on each slip system at a grain by twice-contracted tensorial product between the granular stress $\underline{\sigma}^{\mathrm{s}}$ and the Schmid orientation tensor $\underline{\mathrm{m}}^{\mathrm{s}}$.

$$
\begin{aligned}
\tau^{\mathrm{s}} & =\underline{\sigma}^{\mathrm{g}}: \underline{\mathrm{m}}^{\mathrm{s}} \\
\underline{\mathrm{m}}^{\mathrm{s}} & =\frac{1}{2}\left[\mathrm{n}^{\mathrm{s}} \otimes \mathrm{g}^{\mathrm{s}}+\mathrm{g}^{\mathrm{s}} \otimes \mathrm{n}^{\mathrm{s}}\right]
\end{aligned}
$$

where $\mathrm{g}^{\mathrm{s}}$ is the unit vector in the slip direction and $\mathrm{n}^{\mathrm{s}}$ being the vector normal to the slip plane.

\section{Free Energy and Dissipation Potential}

Under small strain and isothermal conditions, the overall free energy of the system can be partitioned into reversible and irreversible energies per unit volume.

$$
\psi=\psi_{\mathrm{e}}+\psi_{\text {in }}
$$


According to Chadli and Abdul-Latif (2005), the overall elastic and inelastic parts of the total specific free energy can be respectively expressed as a sum of all granular elastic $\left(\psi_{\mathrm{el}}^{\mathrm{g}}\right)$ and inelastic $\left(\psi_{\mathrm{in}}^{\mathrm{g}}\right)$ potentials in the polycrystal:

$$
\begin{aligned}
\rho \psi_{\mathrm{el}} & =\sum_{g=1}^{N_{\mathrm{g}}} \rho \psi_{\mathrm{el}}^{\mathrm{g}} \\
\rho \psi_{\mathrm{in}} & =\sum_{g=1}^{N_{\mathrm{g}}} \rho \psi_{\mathrm{in}}^{\mathrm{g}}
\end{aligned}
$$

The granular elastic behavior is assumed to be uniform, isotropic, and compressible. Thus, its free energy per unit volume can be written as a classical isotropic quadratic function of the granular elastic strain tensor $\underline{\varepsilon}_{\text {el }}^{\mathrm{g}}$ coupled with mesodamage.

$$
\rho \psi_{\mathrm{el}}^{\mathrm{g}}\left(\underline{\varepsilon}_{\mathrm{el}}^{\mathrm{g}}, d^{\mathrm{g}}\right)=\frac{1}{2} \lambda\left(\operatorname{tr}\left(\tilde{\tilde{\varepsilon}}_{\mathrm{el}}^{\mathrm{g}}\right)\right)^{2}+\mu \operatorname{tr}\left(\underline{\tilde{\varepsilon}}_{\mathrm{el}}^{\mathrm{g}}\right)^{2}
$$

where $\lambda$ and $\mu$ are the classical Lame's constants of the grain, and $\rho$ is the material density.

Using the same form proposed by Saanouni and Abdul-Latif (1996), the granular inelastic part of the state potential $\rho \psi_{\text {in }}^{\mathrm{g}}$ is expressed as a quadratic function of the internal variables:

$$
\rho \psi_{\text {in }}^{\mathrm{g}}\left(\underline{\beta}^{\mathrm{g}}, q^{\mathrm{s}}, d^{\mathrm{g}}\right)=\frac{1}{3} C^{\mathrm{g}} \underline{\beta}^{\mathrm{g}}: \underline{\beta}^{\mathrm{g}}+\frac{Q^{\mathrm{s}}\left(1-d^{\mathrm{g}}\right)}{2} \sum_{r=1}^{n} \sum_{s=1}^{n} \mathbf{H}_{\mathrm{rs}} q^{\mathrm{r}} q^{\mathrm{s}}
$$

The intragranular hardening $q^{\mathrm{s}}$ is defined by its of modulus $Q^{\mathrm{s}}$ the introduction. $\mathbf{H}_{\mathrm{rs}}$ is the hardening interaction matrix. This matrix allows the cross influence of the slip of the system $s$ on the hardening of the system $r$, belonging to the same family or not. In this model, a simple $12 \times 12$ matrix is chosen taking into account only the octahedral slips for FCC polycrystals. Note that this relation has been originally proposed by (Abdul-Latif, 1994) according to the introduction of the hardening interaction matrix $\mathbf{H}_{\mathrm{rs}}$ in the state potential instead of dissipation potential. The specific coupling of the granular damage variable in (11) leads clearly to the fact that each slip system is equally affected by damage in a given grain as mentioned above. Besides, it is assumed that the intergranular kinematic hardening is not influenced by damage. 
Based on the granular elastic free energy (10), the granular stress (dual variable) tensor $\underline{\sigma}^{\mathrm{g}}$ can be deduced by:

$$
\underline{\sigma}^{\mathrm{g}}=\rho \frac{\partial \psi_{\mathrm{el}}^{\mathrm{g}}}{\partial \underline{\mathrm{el}}_{\mathrm{el}}^{\mathrm{g}}}=2 \mu \underline{\varepsilon}_{\mathrm{el}}^{\mathrm{g}}+\lambda\left(\operatorname{tr} \underline{\tilde{\varepsilon}}_{\mathrm{el}}^{\mathrm{g}}\right) \underline{1}
$$

It can also be rewritten as:

$$
\underline{\varepsilon}_{\mathrm{el}}^{\mathrm{g}}=\frac{(1+v)}{\tilde{E}_{\mathrm{g}}} \underline{\sigma}^{\mathrm{g}}-\frac{\nu}{\tilde{E}_{\mathrm{g}}} \operatorname{tr}\left(\underline{\sigma}^{\mathrm{g}}\right) \underline{1}
$$

with

$$
\tilde{E}^{\mathrm{g}}=E^{\mathrm{g}}\left(1-d^{\mathrm{g}}\right)
$$

where $\tilde{E}^{\mathrm{g}}$ is the granular Young's modulus coupled with damage and $v$ the Poisson's ratio for each grain. $\underline{I}$ is the second-order unit tensor.

The dual variables $\underline{x}^{\mathrm{g}}, \bar{Y}$, and $R^{\mathrm{s}}$ (state laws) can be derived from (10) and (11) as follows:

At the mesoscale:

The intergranular kinematic hardening is deduced as:

$$
\underline{x}^{\mathrm{g}}=\rho \frac{\partial \psi_{\mathrm{in}}^{\mathrm{g}}}{\partial \underline{\beta}^{\mathrm{g}}}=\frac{2}{3} C^{\mathrm{g}} \underline{\beta}^{\mathrm{g}}
$$

The mesodamage energy $(\bar{Y})$ is decomposed into elastic and inelastic parts.

$$
\bar{Y}=\bar{Y}_{\mathrm{el}}^{\mathrm{g}}+\bar{Y}_{\mathrm{in}}^{\mathrm{g}}
$$

From (10), the granular elastic energy can be deduced as:

$$
\bar{Y}_{\mathrm{el}}^{\mathrm{g}}=\rho \frac{\partial \psi_{\mathrm{el}}^{\mathrm{g}}}{\partial d^{\mathrm{g}}}=\frac{\lambda}{2}\left(\operatorname{tr} \varepsilon_{\mathrm{el}}^{\mathrm{g}}\right)^{2}+\mu \operatorname{tr}\left(\varepsilon_{\mathrm{el}}^{\mathrm{g} 2}\right)
$$

By substituting (13) in (16), this energy can be expressed as :

$$
\bar{Y}_{\mathrm{el}}^{\mathrm{g}}=\frac{\left(J_{2}\left(\underline{\sigma}^{\mathrm{g}}\right)\right)^{2}}{2 E\left(1-d^{\mathrm{g}}\right)^{2}}\left[\frac{2}{3}(1+v)+3(1-2 v)\left(\frac{\sigma_{\mathrm{h}}^{\mathrm{g}}}{J_{2}\left(\underline{\sigma}^{\mathrm{g}}\right)}\right)^{2}\right]
$$


with

$$
\sigma_{\mathrm{h}}^{\mathrm{g}}=\frac{\sigma_{11}^{\mathrm{g}}+\sigma_{22}^{\mathrm{g}}+\sigma_{33}^{\mathrm{g}}}{3}
$$

The effect of the stress triaxiality on the mesodamage evolution is governed by the ratio $\left(\sigma_{\mathrm{h}}^{\mathrm{g}} / J_{2}\left(\underline{\sigma}^{\mathrm{g}}\right)\right)$ given in (17).

According to the theoretical assumption given in (11), the granular inelastic energy depends entirely on the intragranular isotropic hardening:

$$
\bar{Y}_{\mathrm{in}}^{\mathrm{g}}=\frac{Q^{\mathrm{s}}}{2} \sum_{r=1}^{n} \sum_{s=1}^{n} H_{\mathrm{rs}} q^{\mathrm{s}} q^{\mathrm{r}}
$$

At the microscale:

The hardening variables coupled with mesodamage can be defined by

$$
R^{\mathrm{s}}=\rho \frac{\partial \psi_{\mathrm{in}}^{\mathrm{g}}}{\partial q^{\mathrm{s}}}=Q^{\mathrm{s}}\left(1-d^{\mathrm{g}}\right) \sum_{r=1}^{n} \mathbf{H}_{\mathrm{rs}} q^{\mathrm{r}}
$$

At the ss level, with the presence of mesodamage, a slip system becomes active once the effective resolved stress reaches a critical stress on the slip system:

$$
\tilde{f}^{\mathrm{s}}=\frac{\left|\tau^{\mathrm{s}}\right|}{\sqrt{1-d^{\mathrm{g}}}}-\frac{R^{\mathrm{s}}}{\sqrt{1-d^{\mathrm{g}}}}-k_{\mathrm{o}}^{\mathrm{s}}
$$

where $k_{\mathrm{o}}^{\mathrm{s}}$ is the initial value of the critical resolved shear stress.

Considering the non-associated plasticity concept, the evolution rates can be obtained by the introduction of the inelastic dissipation potential coupled with damage $\tilde{F}$ for each slip system. With a new mesodamage initiation criterion, this potential can be written as:

$$
\begin{aligned}
\tilde{F}= & \tilde{f}^{\mathrm{s}}+\frac{3 a^{\mathrm{g}}}{4 C^{\mathrm{g}}} \underline{x}^{\mathrm{g}} \underline{x}^{\mathrm{g}}+b^{\mathrm{s}} q^{\mathrm{s}} \frac{R^{\mathrm{s}}}{\sqrt{1-d^{\mathrm{g}}}} \\
& +\frac{S^{\mathrm{g}}}{S_{\mathrm{o}}^{\mathrm{g}}+1}\left(\frac{\bar{Y}^{\mathrm{g}}}{S^{\mathrm{g}}}\right)^{S_{\mathrm{o}}^{\mathrm{g}}+1} \frac{\mathrm{H}\left(\left(1-\left(N_{\mathrm{sp}} / N_{\mathrm{st}}\right)\right)^{-\mathrm{m}} P^{\mathrm{g}}-P_{\mathrm{th}}^{\mathrm{g}}\right)}{\left(1-d^{\mathrm{g}}\right)^{\mathrm{w}}}
\end{aligned}
$$

where $a^{\mathrm{g}}$ and $b^{\mathrm{s}}$ characterize the non-linearity of the intergranular kinematic and intragranular isotropic hardenings, respectively. $p^{\mathrm{g}}$ is the granular 
accumulated plastic strain, $S^{\mathrm{g}}, S_{\mathrm{o}}^{\mathrm{g}}$, and $w$ are material constants characterizing the mesodamage mechanism. $\mathrm{H}$ (..) is the classical Heaviside function. A recent work (Chadli and Abdul-Latif, 2005) shows that the fatigue damage initiation criterion $\mathrm{H}\left(P^{\mathrm{g}}-P_{\mathrm{th}}^{\mathrm{g}}\right)$ gives different fatigue lives. These predicted lives obtained under several cyclic loading conditions having the same equivalent strain are not in a suitable adequacy with the experimental observations. Therefore, a new proposed damage criterion $\mathrm{H}\left(\left(1-\left(N_{\mathrm{sp}} / N_{\mathrm{st}}\right)\right)^{-\mathrm{m}} P^{\mathrm{g}}-P_{\mathrm{th}}^{\mathrm{g}}\right)$ depends not only on the granular accumulated plastic strain, but also on the applied loading nature described explicitly by the ratio $\left(N_{\mathrm{sp}} / N_{\mathrm{st}}\right)$. Related to this criterion, the fatigue damage can be nucleated when $\left[P^{\mathrm{g}}\left(1-\left(N_{\mathrm{sp}} / N_{\mathrm{st}}\right)\right)^{-\mathrm{m}}\right]>P_{\mathrm{th}}^{\mathrm{g}} . P_{\mathrm{th}}^{\mathrm{g}}$ represents a threshold of the granular accumulated plastic strain, $N_{\mathrm{sp}}$ the number of the activated plastic slips, and $N_{\text {st }}$ the total number of slip systems in the polycrystal. Figure 1 demonstrates schematically a representation of this new criterion where the point of damage initiation corresponds to the intersection point between the curves representing $\left(1-\left(N_{\mathrm{sp}} / N_{\mathrm{st}}\right)\right)^{-\mathrm{m}}$ and $P^{\mathrm{g}} / P_{\mathrm{th}}^{\mathrm{g}}$ versus the granular inelastic accumulated plastic strain $P^{\mathrm{g}}$.

The equations of the internal variables evolution rate $\left(\dot{\beta}^{\mathrm{g}}, \dot{d}^{\mathrm{g}}\right.$, and $\left.\dot{q}^{\mathrm{s}}\right)$ should now be determined. Their evolution laws are derived by the generalized normality rule:

At the mesoscale:

The granular inelastic strain can be defined as:

$$
\dot{\varepsilon}_{\mathrm{in}}^{\mathrm{g}}=\sum_{s=1}^{n} \dot{\lambda^{\mathrm{s}}} \frac{\partial \tilde{F}^{\mathrm{s}}}{\partial \underline{\sigma}^{\mathrm{g}}}=\sum_{s=1}^{n} \frac{\dot{\lambda^{\mathrm{s}}}}{\sqrt{1-d^{\mathrm{g}}}} \operatorname{sign}\left(\tau^{\mathrm{s}}\right) \underline{m}^{\mathrm{s}}
$$

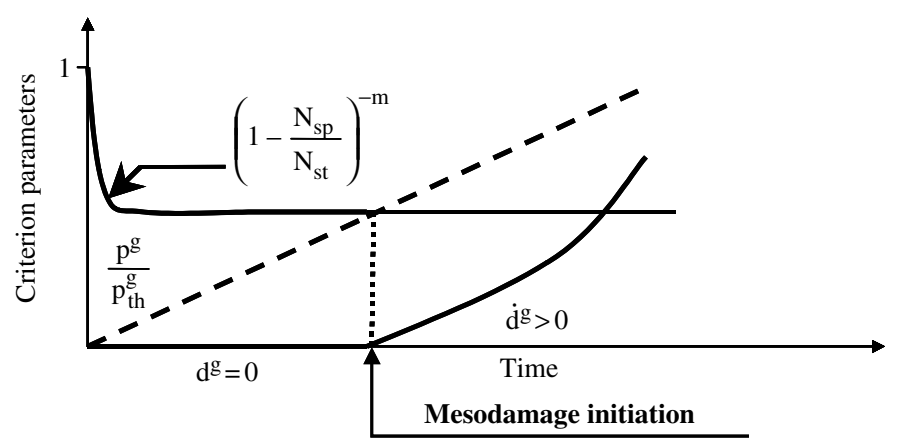

Figure 1. Schematic representation of the new mesodamage initiation criterion. 
Without damage effect, the evolution of the kinematic intergranular hardening variable $\left(\underline{\beta}^{\mathrm{g}}\right)$ is defined as:

$$
\underline{\dot{\beta}}^{\mathrm{g}}=-\sum_{r=1}^{n} \dot{\lambda} \mathrm{s} \frac{\partial \tilde{F}^{\mathrm{s}}}{\partial \underline{x}^{\mathrm{g}}}=\dot{\varepsilon}_{\mathrm{in}}^{\mathrm{g}}-a^{\mathrm{g}} \underline{\beta}^{\mathrm{g}} \sum_{s=1}^{n} \dot{\lambda} \mathrm{s}
$$

The mesodamage rate can be written as:

$$
\dot{d}^{\mathrm{g}}=-\sum_{r=1}^{n} \dot{\lambda}^{\mathrm{s}} \frac{\partial \tilde{F}^{\mathrm{s}}}{\partial \bar{Y}^{\mathrm{g}}}=\left(\frac{\bar{Y}^{\mathrm{g}}}{S^{\mathrm{g}}}\right)^{S_{\mathrm{o}}^{\mathrm{s}}} \frac{\sum_{s=1}^{n} \dot{\lambda}^{\mathrm{s}}}{\left(1-d^{\mathrm{g}}\right)^{\mathrm{w}}} \mathrm{H}\left(\left(1-\frac{N_{\mathrm{sp}}}{N_{\mathrm{st}}}\right)^{-\mathrm{m}} P^{\mathrm{g}}-P_{\mathrm{th}}^{\mathrm{g}}\right)
$$

At the microscale:

The intragranular isotropic hardening is deduced as:

$$
\dot{q}^{\mathrm{s}}=-\sum_{r=1}^{n} \dot{\lambda}^{\mathrm{r}} \frac{\partial F^{\mathrm{r}}}{\partial R^{\mathrm{r}}}=\frac{\dot{\lambda}^{\mathrm{s}}}{\sqrt{1-d^{\mathrm{g}}}}\left(1-b^{\mathrm{s}} q^{\mathrm{s}}\right)
$$

In the framework of viscoplasticity, the glide of dislocations coupled with mesodamage (Schmid type) occurs along closed-packed crystallographic slip planes and directions, with the continuum viscoplastic shearing rate on the slip system $s$, given by:

$$
\dot{\lambda}^{\mathrm{s}}=\left(\frac{\tilde{f}^{\mathrm{s}}}{K^{\mathrm{s}}}\right)^{z^{\mathrm{s}}}=\left(\frac{\left(\left|\tau^{\mathrm{s}}\right| / \sqrt{1-d^{\mathrm{g}}}\right)-\left(R^{\mathrm{s}} / \sqrt{1-d^{\mathrm{g}}}\right)-k_{\mathrm{o}}^{\mathrm{s}}}{K^{\mathrm{s}}}\right)^{z^{\mathrm{s}}}
$$

where $K^{\mathrm{s}}$ and $z^{\mathrm{s}}$ are material constants describing the local viscous effect of the material.

\section{Overall Constitutive Relations}

The transition from the single to the polycrystal response is performed by averaging procedures depending on the granular rates. In this framework, the overall elastic and inelastic strain tensors are obtained through the micro-macro methodology. It is worth emphasizing that the presence of the damage and its coupling with the elastic behavior lead consequently to a certain modification in its homogenization process as obviously noted in Chadli and Abdul-Latif (2005). According to their 
analysis, the overall elastic strain rate $\left(\underline{\dot{E}}^{\mathrm{e}}\right)$ coupled with damage can be expressed as :

$$
\dot{E}^{\mathrm{e}}=\sum_{\mathrm{g}=1}^{N_{\mathrm{g}}^{\prime}} v_{\mathrm{g}}^{\prime}\left(\frac{\tilde{E}^{\mathrm{g}}}{\tilde{E}^{\mathrm{h}}}\right) \dot{\underline{\varepsilon}}_{\mathrm{el}}^{\mathrm{g}}
$$

where $\left(\tilde{E}^{\mathrm{g}} / \tilde{E}^{\mathrm{h}}\right)$ represents a correction term taking into account the nonlinearity effect induced by damage. For further discussion about the theoretical foundation of Equation (27), the reader is referred to the reference given above. In the case of a totally damaged grain (i.e., $d^{\mathrm{g}}=d_{\mathrm{cr}}^{\mathrm{g}}$ ), such a grain cannot support any load and it loses its elastic strain. Hence, it is considered here (with the damaged configuration) that the transition from the single to the polycrystal response of the elastic strain is performed by using the notion of no totally damaged grains $\left(N_{\mathrm{g}}^{\prime}\right)$ and their volume fraction $\left(v_{\mathrm{g}}^{\prime}\right)$.

On the other hand, a totally damaged grain always conserves its plastic strain history. Thus, the overall inelastic strain rate $\left(\underline{\dot{E}}^{\dot{i n}}\right)$ is deduced from the following equation:

$$
\underline{\dot{E}}^{\text {in }}=\sum_{g=1}^{N_{\mathrm{g}}} v^{\mathrm{g}} \underline{\dot{\varepsilon}}_{\mathrm{in}}^{\mathrm{g}}
$$

Using the small strain assumption, the overall total strain rate $(\underline{\dot{E}})$ is thus determined by:

$$
\underline{\dot{E}}=\underline{\dot{E}}^{\mathrm{e}}+\underline{\dot{E}}^{\text {in }}
$$

Under the same experimental conditions for a given material, it is well known that the repetition of several fatigue tests leads, undoubtedly, to different fatigue lives. These lives follow in general a probability law. The damage configuration of a polycrystal, under which the overall damage initiation can be defined, is now necessary. Consequently, proposing an adequate solution for this problem is not always a simple task, a priori, notably when the physical and theoretical framework should be respected. The resorting to a probability law represents a suitable approach in developing an acceptable solution justified by the experimental results. Hence, the law proposed initially by Weibull is adopted in this work. For the sake of theoretical simplicity, it is assumed that this law can be applied to describe the overall damage initiation criterion. Therefore, a polycrystal can be damaged, when its damaged energy at the macroscale $\left(\bar{Y}^{\text {tot }}\right)$ attains 
a critical value $\left(Y_{\mathrm{u}}\right)$. The totally damaged polycrystal condition takes place when the probability $\left(P_{\mathrm{f}}\right)$ is almost equal to one.

$$
P_{\mathrm{f}}=1-\exp \left[-\frac{1}{V_{0}} \int_{\Omega}\left(\frac{\bar{Y}^{\mathrm{tot}}-Y_{\mathrm{u}}}{Y_{\mathrm{o}}}\right)^{\alpha} d V\right]
$$

It is assumed that all the grains within a polycrystal (aggregate) occupy the domain $(\Omega)$ and have the same volume $\left(\Omega^{\mathrm{g}}\right)$. This hypothesis allows concluding the following relation:

$$
P_{\mathrm{f}}=1-\exp \left[-\frac{1}{V} \sum_{g=1}^{N_{\mathrm{g}}} \int_{\Omega^{\mathrm{g}}}\left(\frac{\bar{Y}^{\mathrm{tot}}-Y_{\mathrm{u}}}{Y_{\mathrm{o}}}\right)^{\alpha} d V\right]
$$

It is also adopted that the homogeneity of damage energy in a given grain $g$ of the polycrystal is verified. Thus, the simplified definition of the macroscopic damage initiation criterion can be described by:

$$
P_{\mathrm{f}}=P\left(\bar{Y}_{\mathrm{r}}^{\mathrm{tot}} \geq \bar{Y}^{\mathrm{tot}}\right)=1-\exp \left[-\sum_{g=1}^{N_{\mathrm{g}}} \frac{V^{\mathrm{g}}}{V}\left(\frac{\bar{Y}^{\mathrm{g}}-Y_{\mathrm{u}}}{Y_{\mathrm{o}}}\right)^{\alpha}\right]
$$

where $\bar{Y}_{\mathrm{r}}^{\text {tot }}$ is the damaging energy, $Y_{\mathrm{o}}$ is a scale parameter, and $\alpha$ is a material parameter controlling the linearity of this probability.

\section{EXPERIMENTAL PROGRAM}

All the experiments are performed on the well-known aluminum alloy 2024 (noted: Al-2024). The tests are carried out at room temperature on a servo-hydraulic INSTRON machine (type 1340), using thin-walled tubes (internal diameter: $15 \mathrm{~mm}$, external diameter: $18 \mathrm{~mm}$ ). Different uniaxial and biaxial loading paths, with a triangle waveform, are conducted up to the final fracture of the specimen. The maximum von-Mises equivalent total strain is defined as :

$$
\begin{aligned}
\text { For uniaxial tension-compression test : } & \varepsilon_{\mathrm{eq}_{\max }^{\mathrm{t}}}^{\mathrm{t}}=\frac{\varepsilon_{\max }-\varepsilon_{\min }}{2} \\
\text { For biaxial tension-torsion test : } & \varepsilon_{\mathrm{eq}_{\max }^{\mathrm{t}}}^{\mathrm{t}}=\max \left(\sqrt{\varepsilon^{2}+\frac{\gamma^{2}}{3}}\right)
\end{aligned}
$$

where $\varepsilon$ is the macroscopic normal strain and $\gamma$ the macroscopic shear strain. 
Table 1. Chemical composition of aluminum alloy 2024 (\% in weight).

\begin{tabular}{lccccccccccc}
\hline Al & $\mathrm{Si}$ & $\mathrm{Fe}$ & $\mathrm{Cu}$ & $\mathrm{Mn}$ & $\mathrm{Mg}$ & $\mathrm{Cr}$ & $\mathrm{Ni}$ & $\mathrm{Zn}$ & $\mathrm{Ti}$ & $\mathrm{Zr}$ & $\mathrm{Pb}$ \\
\hline Balance & 0.11 & 0.28 & 4.33 & 0.75 & 1.31 & 0.01 & 0.01 & 0.10 & 0.03 & 0.14 & 0.0021 \\
\hline
\end{tabular}

The specimens are machined from a circular bar with an outer diameter of $42 \mathrm{~mm}$ in the longitudinal direction. They are polished to avoid crack initiation on manufacturing steps. After the machining process, all the specimens undergo an over-aging heat treatment (noted OA). This treatment consists of setting the specimens in solution at $495^{\circ} \mathrm{C}$, followed by a water quench. The chemical composition of the alloy is given in Table 1.

In this study, several cyclic tests are carried out. They are uniaxial tension-compression (noted TC), torsion-torsion (AT), biaxial loading of tension-torsion with $90^{\circ}$ out-of-phase angle (TT90), and butterfly test (Fly), represented schematically in Figure 2.

The first test is initially performed in TC with two strain levels. First, under a total strain-controlled condition of $\Delta \varepsilon_{11}=1 \%, 7000$ cycles are realized. Then, $\Delta \varepsilon_{11}=2 \%$ is applied until the final fatigue failure of 228 cycles giving a total fatigue life of 7228 cycles. Three uniaxial cyclic loadings of various total strain amplitudes $\left(\Delta \varepsilon_{11}=1.7 \%\right.$ (a period of $\left.20 \mathrm{~s}\right)$, $2 \%$ (a period of $50 \mathrm{~s}$ ), and 3\% (a period of $20 \mathrm{~s})$ ) are applied.

These tests are naturally stopped at the instant of the specimen failure (appearance of a macro-crack on the free face of the specimen (Figure 3). The corresponding fatigue lives $\left(N_{\mathrm{f}}\right)$ of these uniaxial loadings are respectively 390, 291, and 73 cycles. Moreover, two biaxial loading paths TT90 are carried out employing two different total strain equivalents $\varepsilon_{\text {eq }}^{\mathrm{t}} \mathrm{max}=0.85$ and $1 \%$ (having a period of $40 \mathrm{~s}$ ), related respectively to two couples of values: $\Delta \varepsilon_{11}=1.7 \%$ and $\gamma_{12}=2.94 \%$ and $\Delta \varepsilon_{11}=2 \%$ and $\gamma_{12}=3.4 \%$. The recorded fatigue lives are 195 and 81 cycles, respectively. The specimen is cycled under the butterfly test with an equivalent total strain of $0.85 \%\left(\Delta \varepsilon_{11}=1.47 \%\right.$ and $\left.\gamma_{12}=1.47 \%\right)$ with $N_{\mathrm{f}}=78$ cycles. The period of the axial strain is $100 \mathrm{~s}$ and that of the shear one is $50 \mathrm{~s}$. A torsion-torsion cyclic loading (AT) is realized having a shear strain-controlled amplitude of $1.46 \%$ (corresponding to $\varepsilon_{\text {eq }}^{\mathrm{t}}=0.85 \%$ ). This test shows that the material fatigue life becomes more significant in comparison to the other loadings, i.e., $N_{\mathrm{f}}=564$ cycles.

To compare the material behavior under these different loading paths used in this study, Figure 4 displays four curves, representing the evolution of the maximum von-Mises equivalent overall stress for TC, AT, TT90, and 


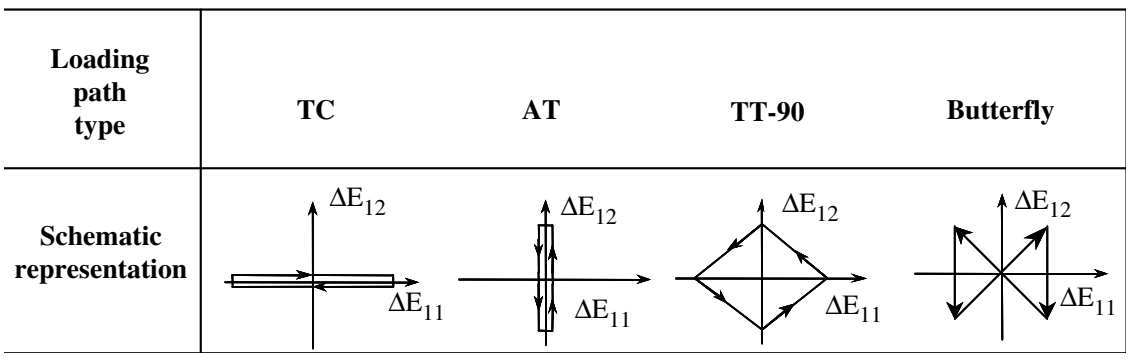

Figure 2. Employed cyclic loading paths.

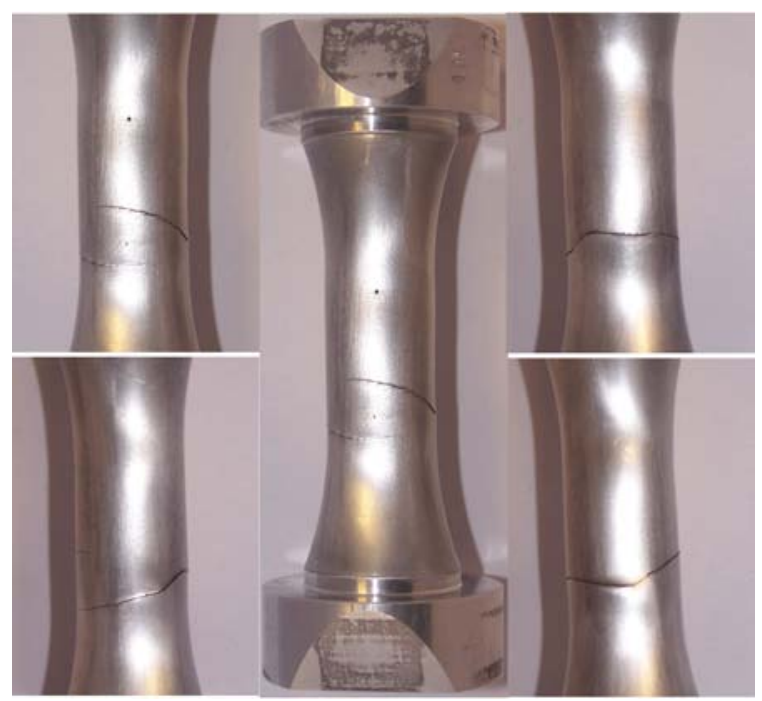

Figure 3. General view of a specimen at the end of its life showing various profiles.

butterfly during cycling. Note that the maximum von-Mises equivalent strain $\varepsilon_{\mathrm{eq}_{\max }^{\mathrm{t}}}$ for such loadings has a value of $0.85 \%$. It is clear that the cyclic hardening behavior of Al-2024 under butterfly test is more important than that of TT90. Nevertheless, the duration of the cyclic steady state phase is the shortest. One can explain this phenomenon by a competition between the highest cyclic hardening and the highest softening mechanisms due to the material damaging.

To study the strain amplitude effect on the cyclic plasticity and fatigue life under TC, three amplitudes $\Delta \varepsilon_{11}=1.7,2$, and $3 \%$ are tested. The wellknown linear Manson-Coffin relation is shown in Figure 5 with a slope of -0.33 . Furthermore, an examination of Figure 6 demonstrates that the cyclic hardening increases with the rising of the strain amplitude. In other 


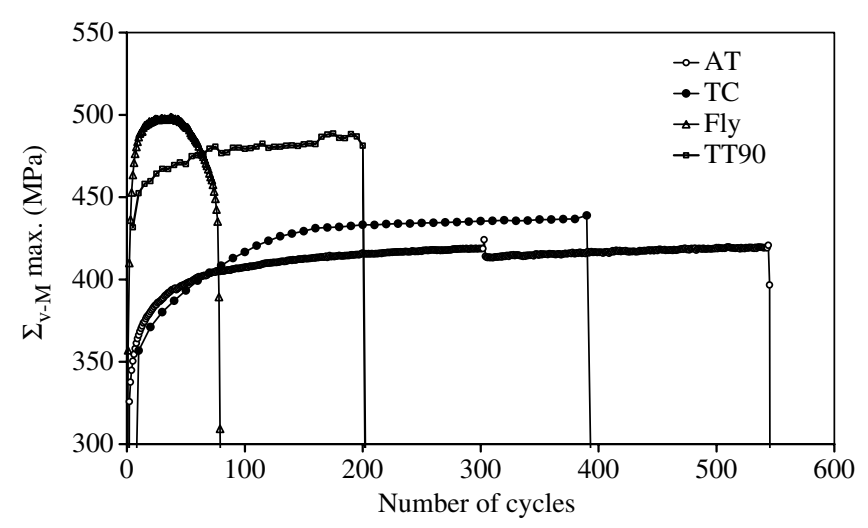

Figure 4. Experimental evolution of the maximum von-Mises equivalent stress up to the final fracture under various cyclic loading types.

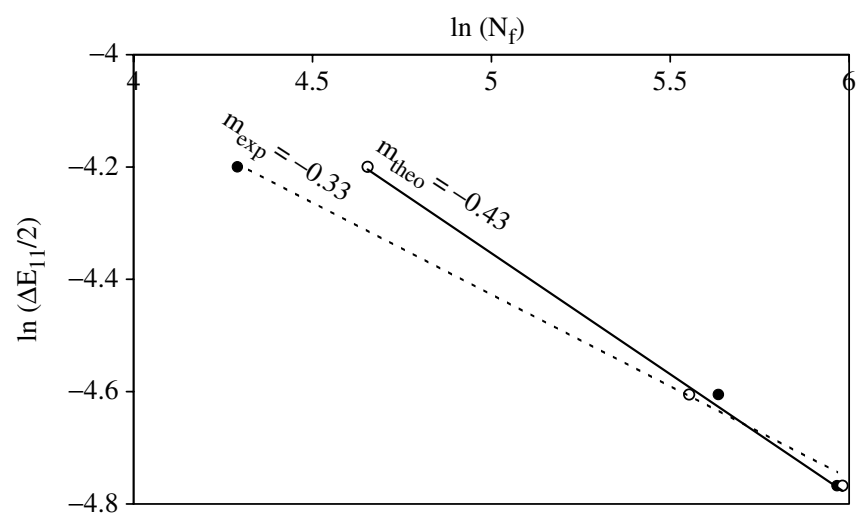

Figure 5. Manson-Coffin relation.

words, with $\Delta \varepsilon_{11}=1.7 \%$, the corresponding maximum stress is $435 \mathrm{MPa}$, whereas for $\Delta \varepsilon_{11}=2$ and $3 \%$, the maximum stresses are 445 and $485 \mathrm{MPa}$, respectively.

During certain tests, the unilateral phenomenon of damage is obviously noted along the specimen axis notably in TC with $\Delta \varepsilon_{11}=2.0 \%$, TT90, and butterfly (for example, see Figure 7). In fact, after damage initiation, the material behavior is not symmetrical any more; the Young's modulus is not the same in tension as in compression phase. The opening of damages (in tension) takes place in the direction normal with the specimen axis, whereas during their closures (in compression), the material behaves passively vis-à-vis the damage, i.e., damage deactivation 


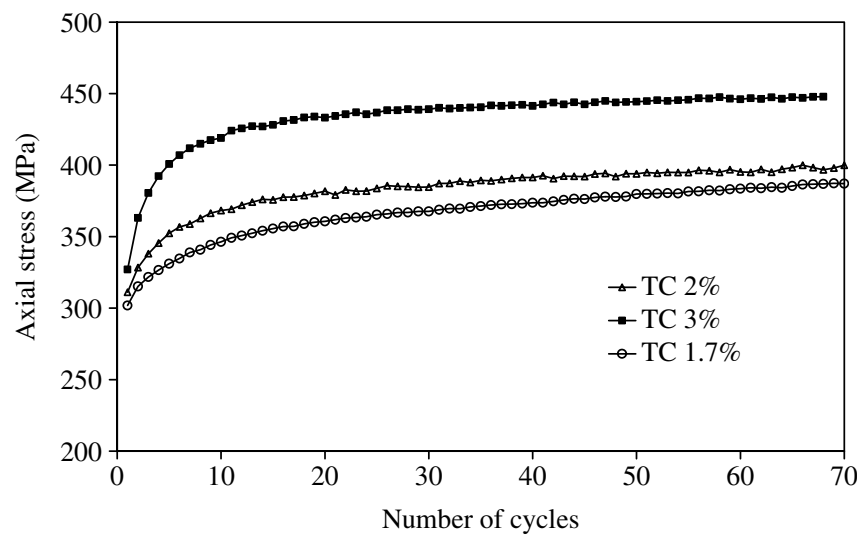

Figure 6. Evolution of axial stress $\Sigma_{11}$ for a loading TC with different strain amplitudes.

(a)

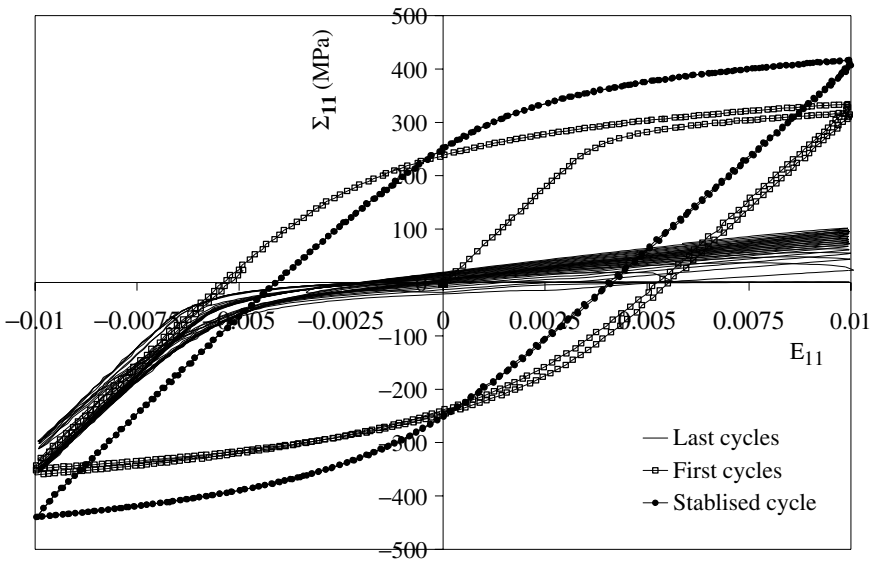

(b)

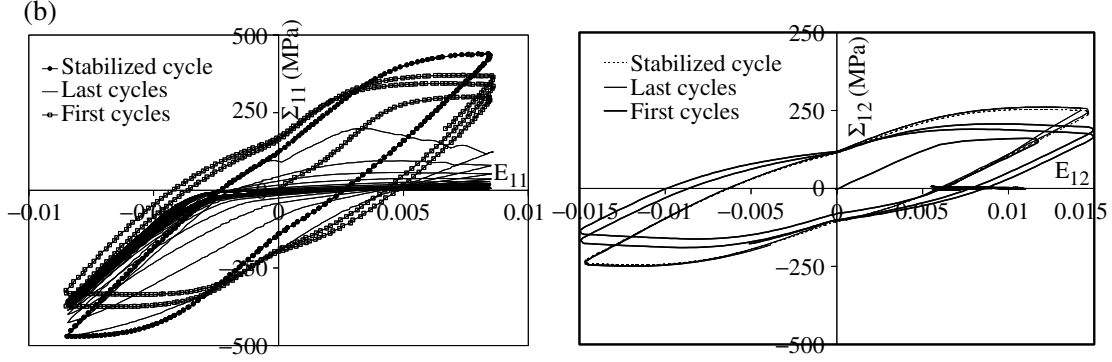

Figure 7. Cyclic response of aluminum 2024 under: (a) TC and (b) TT90. 
phenomenon occurs. It is noteworthy that the shear component (in biaxial loading case) does not undergo the unilateral damage effect for this material under these employed loading paths (Figure 7(b)). This means that it evolves in a bilateral manner. Moreover, this unilateral damage effect is not taken in to account by the proposed model.

\section{APPLICATION OF THE DEVELOPED MODEL}

\section{Material Constants Determination}

The abilities of the developed model in describing the effect of loading path on the cyclic plasticity and fatigue behaviors are described here.

In order to simplify the model complexity, it is supposed that all the grains have the same constants (elasticity: $E, v$; inelasticity: $C^{\mathrm{g}}, a^{\mathrm{g}}$, and damage: $s^{\mathrm{g}}, s_{\mathrm{o}}^{\mathrm{g}}, w, m, P_{\mathrm{th}}^{\mathrm{g}}, Y_{\mathrm{th}}, Y_{\mathrm{o}}$, and $\alpha$ ) and all the slip systems have also the same constants $z^{\mathrm{s}}, K^{\mathrm{s}}, k_{\mathrm{o}}^{\mathrm{s}}, Q^{\mathrm{s}}$, and $b^{\mathrm{s}}$. The hardening interaction matrix $\mathbf{H}_{\mathrm{rs}}$ has six constants $\left(h_{1}, h_{2}, h_{3}, h_{4}, h_{5}, h_{6}\right)$.

First, the model constitutive equations are programmed into a computer code. It is used to calibrate the model parameters based on the resolution technique of the non-linear optimization problem. In fact, gradient algorithm (iterative method) is employed to determine these parameters. The experimental results from the first cycle up to the stabilized one are considered in calibrating the cyclic elasto-inelastic behavior parameters of Al-2024 at room temperature. The elastic coefficients the Young's modulus $(E)$ and the Poisson's ratio $(v)$ are macroscopically determined and it is assumed, for a virgin material, that each grain has the same elastic properties as the polycrystal, i.e., the granular coefficients $\left(E^{\mathrm{g}}\right.$ and $\left.\nu^{\mathrm{g}}\right)$ are equal to their macroscopic ones. Although, the model is a viscoplastic type, the plastic behavior can be described by choosing a relatively high value of viscous exponent $z^{\mathrm{s}}$ and a low value of the coefficient $K^{\text {s }}$, i.e., minimizing the viscosity effect.

The intergranular kinematic hardening coefficients $\left(C^{\mathrm{g}}\right.$ and $\left.a^{\mathrm{g}}\right)$, the initial yield stress of the slip system $k_{\mathrm{o}}^{\mathrm{s}}$ and the intragranular isotropic hardening coefficients $\left(Q^{\mathrm{S}}\right.$ and $\left.b^{\mathrm{s}}\right)$ should be also determined. In addition, six coefficients of the $\mathbf{H}_{\mathrm{rs}}$ matrix $\left(h_{1}, h_{2}, \ldots, h_{6}\right)$ need identification. The diagonal term $\left(h_{1}\right)$ is always equal to one. An initially random crystal distribution of 400 grains is practically an optimum compromise (i.e., giving accurate predictions for reasonable CPU time) as it has been shown in (Abdul-Latif, 2004). Note that the optimized material coefficients are specified as a best fit between the predicted and experimental results (Figure 8). The calibrated parameters for this alloy are summarized in Table 2. 
(a)

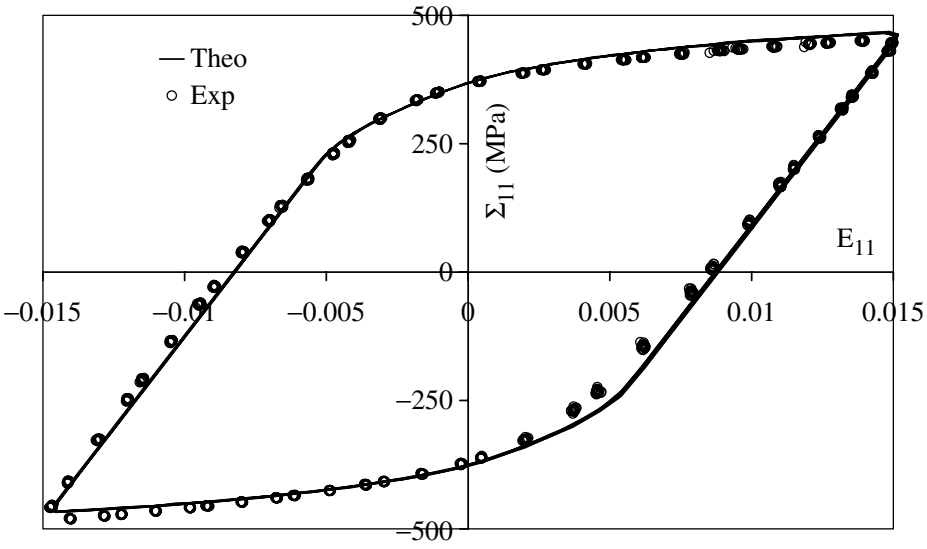

(b)

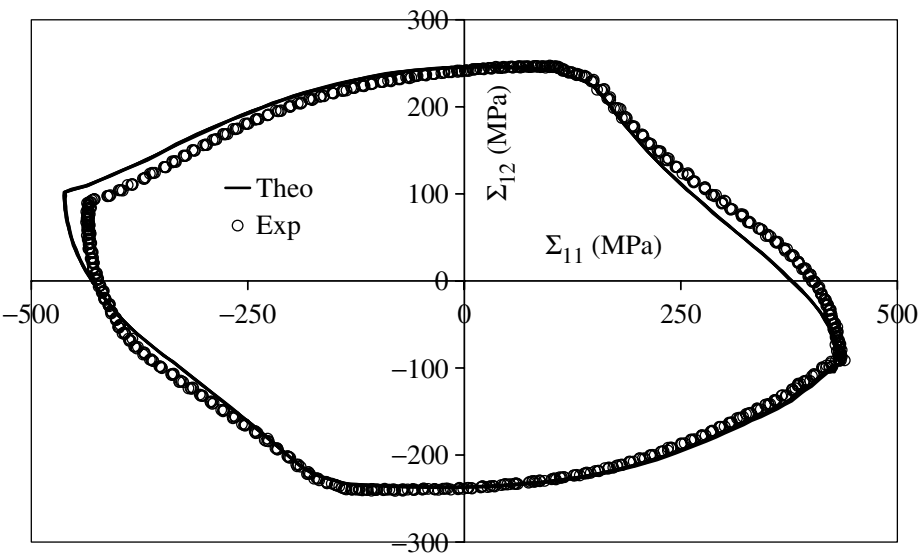

Figure 8. Comparison between the model response and the experimental results for aluminum 2024 (stabilized cycle) under: (a) TC and (b) TT90.

As far as the second step of identification is concerned, the damage coefficients should be defined. This step is realized by fixing all the parameters previously calibrated in the first step. Based on some experimental observations carried out by several researchers in particular Ferney (1994), some parameters are initially determined such as the accumulated plastic strain before mesodamage initiation and the number of activated plastic systems under various cyclic loadings. Once the mesodamage initiation criterion parameters are calibrated, the mesodamage energies permit to deduce subsequently the suitable values of the macrocrack initiation criterion parameters. All the calibrated coefficients related to damage are also gathered in Table 2. 
Table 2. Identified model constants of the aluminum 2024.

\begin{tabular}{lccc}
\hline$E^{\mathrm{g}}(\mathrm{MPa})$ & 71532 & $v$ & 0.3 \\
$C^{\mathrm{g}}(\mathrm{MPa})$ & 32241 & $a^{\mathrm{g}}$ & 48.3 \\
$k_{\mathrm{o}}^{\mathrm{s}}(\mathrm{MPa})$ & 49.8 & $z^{\mathrm{s}}$ & 14.26 \\
$K^{\mathrm{s}}$ & 93.6 & $Q^{\mathrm{s}}(\mathrm{MPa})$ & 475 \\
$b^{\mathrm{s}}$ & 26.2 & $h_{3}$ & 1.32 \\
$h_{2}$ & 1.36 & $h_{5}$ & 1.11 \\
$h_{4}$ & 1.0 & $h_{6}$ & 1.58 \\
$w$ & 0.857 & $\mathrm{~m}$ & 0.24 \\
$P_{\text {th }}^{\mathrm{g}}$ & 5.81 & $\alpha$ & 3.9 \\
$s^{\mathrm{g}}$ & 10.28 & $Y_{\mathrm{o}}(\mathrm{J})$ & 960 \\
$S_{\mathrm{o}}^{\mathrm{g}}$ & 2.427 & $Y_{\mathrm{u}}(\mathrm{J})$ & 255.0 \\
\hline
\end{tabular}

\section{Model Applications}

With all these calibrated parameters, several numerical simulations are conducted to predict the elasto-inelastic cyclic damaged behavior of Al-2024 under these different loadings. Hence, a comparison between the experimental and model results displays (Figure 9) that the differences in fatigue lives are quite small. It reveals that fatigue life decreases with the increasing of the applied loading complexity. Hence, the smallest fatigue life (the highest damaging case) takes place in butterfly test ( $N_{\mathrm{f}}=78$ cycles). This is due to the multiplicity of the activated slip systems induced by the change of the loading direction in the course of cycling as shown in Ferney (1994). As a result, one can conclude that the predictions are corroborated by experimental results to describe the overall cyclic responses of Al-2024, i.e., the identified parameters suitably describe, in general, the plastic fatigue behavior of this alloy. Figure 5 illustrates a comparison between Al-2024 behavior and the model prediction, through the Manson-Coffin curve. A careful examination of the data in such a figure points out that, regardless of the differences between the experimental and predicted results, the developed model describes fairly well the Manson-Coffin $\left(\log E^{\mathrm{p}}-\log N_{\mathrm{f}}\right)$ relation giving a theoretical slope of $m=-0.43$, while the experimental value is $m=-0.33$. The difference between the two slopes comes mainly from the first value, i.e., the highest strain amplitude $\left(\Delta \varepsilon_{11}=3 \%\right)$. Whereas, for smaller strain amplitudes $\left(\Delta \varepsilon_{11}=2\right.$ and $\left.1.7 \%\right)$, small differences between predicted and experimental results are recorded.

For thoroughly studying the main predicted features of plastic fatigue, the effect of the loading path particularly on the damage evolution is qualitatively investigated up to final fracture (precisely up to macrocrack initiation) of the 400 -grain polycrystal. Figure 10 describes the variations of the equivalent overall maximum von-Mises stress versus number of cycles 


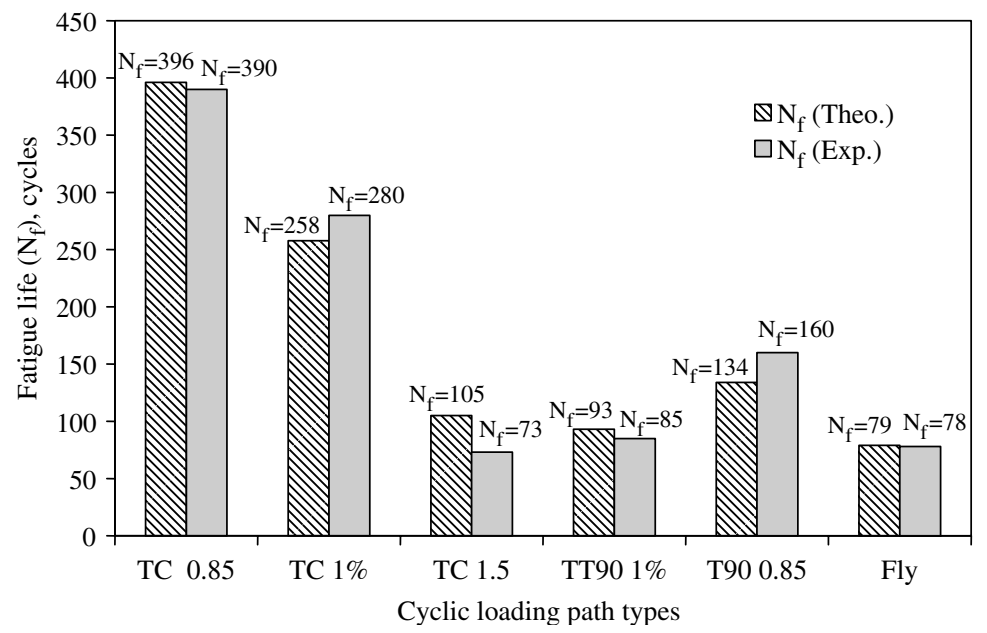

Figure 9. Comparison between the predicted and experimental fatigue lives under different cyclic loading paths for aluminum 2024.

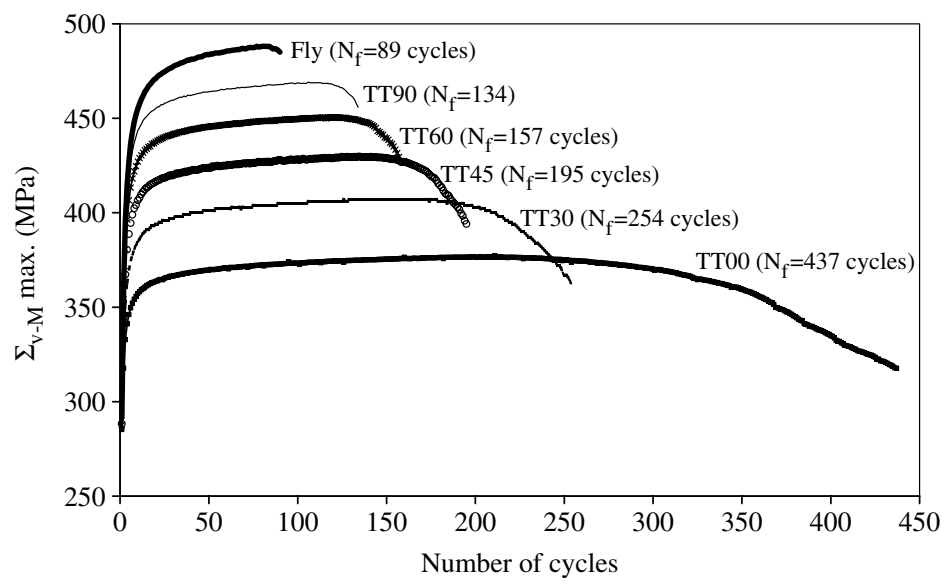

Figure 10. Predicted evolution of the maximum von-Mises equivalent stress up to the final fracture under different biaxial cyclic loading situations.

carried out under different cyclic loading paths. According to Chadli and Abdul-Latif (2005), the initial model shows its ability in characterizing the three well-known macroscopic phases (cyclic hardening, stabilization, and fracture) of plastic fatigue. As a second remark, this figure shows the influence of the loading path complexity on the model response. In tensiontorsion cyclic tests, it is observed that the greater the value of out-of-phase 
angle, the greater the additional hardening becomes. This means that TT90 gives the maximum cyclic hardening. However, in the butterfly test, 316L austenitic stainless steel (Calloch, 1997) and the Al-2024 show experimentally, as examples, that the induced additional hardening becomes more important than that in TT90. In fact, after the hardening phase, the maximum von-Mises equivalent stress at the stabilized phase in butterfly test attains the highest value of certainty. Consequently, this phase has the shortest duration due to the damage effect. The third remark relates to the proportionality of the fatigue life vis-à-vis the cyclic loading complexity. Thus, as an example, $\mathrm{TT}^{1} 0^{1}$ (the simplest biaxial loading) gives the highest fatigue life; while butterfly (the most complex biaxial loading) presents the shortest one. In addition, contrary to those results obtained by the initial version of the model (Chadli and Abdul-Latif, 2005), where the maximal difference between the fatigue lives for different loading conditions has been about $53 \%$, such a difference easily exceeds $390 \%$ with the actual developed model. This significant observation shows explicitly the importance of the two proposed criteria.

To better understand these predictions, the results at the granular level are selected for three loading paths (TT00, TT45, and butterfly). Their elastic and inelastic energy distributions as well as the corresponding stresses are therefore recorded.

As a matter of fact, Figure 11 points out the heterogeneity of the granular elastic energies $\left(Y_{\mathrm{el}}^{\mathrm{g}}\right)$, just before mesodamage initiation, for these three loadings within the 400-grain aggregate. In general, three distinct energy levels are clearly remarked: the lowest one is in TT00, the intermediate value for TT45, and the highest distribution concerns the butterfly loading giving different mean values of $0.8,1.06$, and $1.43 \mathrm{MPa}$, respectively. This remark reflects evidently, once again, the loading path effect on the granular elastic energy level. It is clear that $\left(Y_{\mathrm{el}}^{\mathrm{g}}\right)$ is directly influenced by the granular stress (Equation (17)), i.e., the greater the granular stress value, the greater the granular elastic energy. This result is confirmed by Figure 12 in which the heterogeneous granular stress distributions within the same aggregate at the same moment (just before mesodamage initiation) are illustrated. Three distinct mean stress intensities are also recorded giving $\sigma_{\mathrm{vm}}^{\mathrm{g}}($ Fly $)=479 \mathrm{MPa}>\sigma_{\mathrm{vm}}^{\mathrm{g}}\left(\right.$ TT45) $=400 \mathrm{MPa}>\sigma_{\mathrm{vm}}^{\mathrm{g}}(\mathrm{TT} 00)=350 \mathrm{MPa}$.

As far as the inelastic part of granular energy is concerned, its distribution is appropriately displayed in Figure 13. Such a distribution within the aggregate is more heterogeneous than that of the elastic part. In fact, the inelastic energy values vary between 0.4 and $17 \mathrm{MPa}$, whereas for the elastic

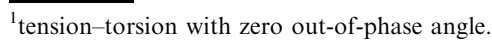




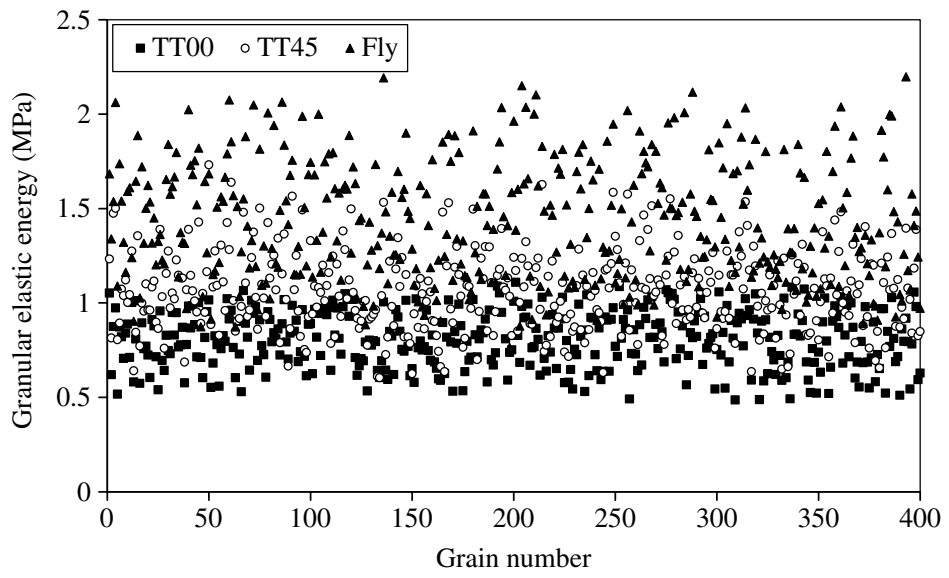

Figure 11. Prediction of the granular distributions of the elastic energy just before mesodamage initiation within 400-grain aggregate under TTO0, TT45, and butterfly cyclic loading paths.

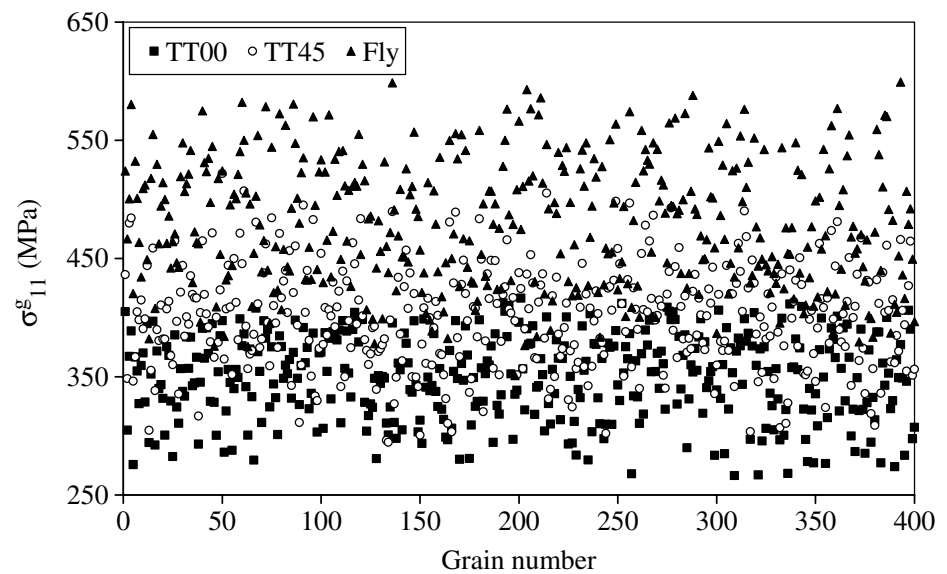

Figure 12. Prediction of the granular stress distributions just before mesodamage initiation within 400-grain aggregate under TT00, TT45, and butterfly cyclic loading paths.

part, its distribution remains between 0.5 and $2.3 \mathrm{MPa}$, as shown in Figure 11. However, the loading path effect is similar for the two parts, i.e., more significant energies for more complex loadings. Moreover, the role of the inelastic part of energy is more important than that of elastic one whatever the applied loading type. The direct consequence of this finding is that the damage is more controlled by the inelastic part, which is a function of the intragranular isotropic hardening variable $R^{\mathrm{s}}$ (Equation (18)). 


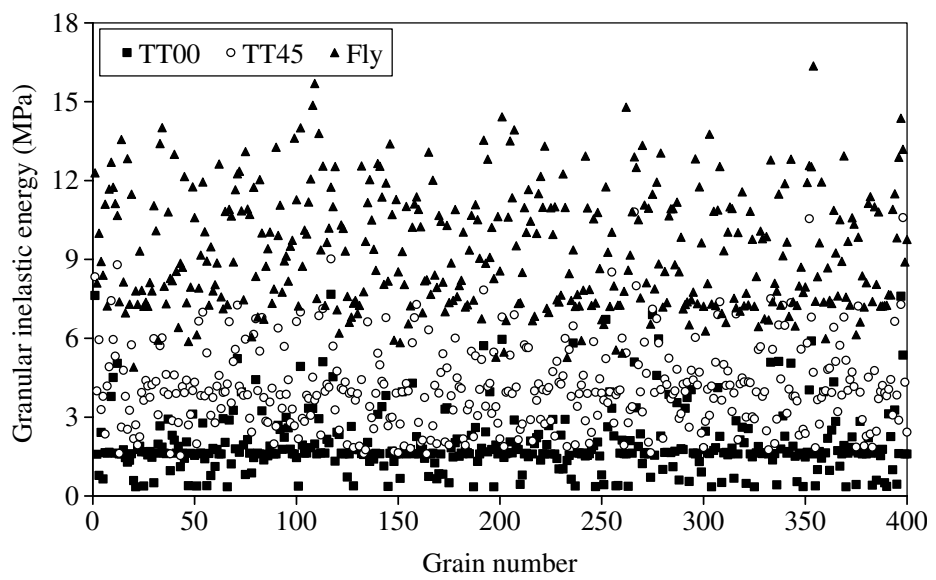

Figure 13. Prediction of the granular distributions of the inelastic energy just before mesodamage initiation within 400-grain aggregate under TTO0, TT45, and butterfly cyclic loading paths.

\section{CONCLUSIONS}

The main objective of this study is to predict the low-cycle fatigue behavior for those FCC polycrystals having a noticeable sensitivity to the cyclic loading paths like aluminum 2024 (Al-2024). The developed model is expressed in the time dependent plasticity for a small strain assumption. It is assumed that the isotropic mesodamage variable $\left(d^{\mathrm{g}}\right)$ initiates and then evolves. Some theoretical limitations have been obviously observed in the model recently proposed by Chadli and Abdul-Latif (2005). Hence, a new strategy is exploited in various cyclic loading configurations in order to explore different possibilities offered to describe the damaged behavior. In this context, one of the possible ways of modeling consists in developing two new aspects:

1. mesodamage initiation criterion depending on the granular cumulated plastic strain as well as on the applied loading's path;

2. macrocrack initiation criterion via the probabilistic approach of Weibull type.

This gives us at the end a mixed approach with double character (micromechanical-probabilistic).

After introducing the damage variable at each level, the coupling behavior-damage is then accomplished using the concept of the effective state variables. These are based on the hypothesis of energy equivalence. 
Several quantitative comparisons (model-experiment) are presented to validate the model capability. They are based on experimental observations of low-cycle fatigue for Al-2024. These experiments are carried out under uniaxial and multiaxial loading paths. It is obvious that the whole obtained results are interesting.

The qualitative application of the model under different complex cyclic loading situations reveals its ability to take into account correctly the principal phenomena observed in plastic fatigue: (i) the loading amplitude effect, i.e., the greater the loading amplitude, the greater the additional hardening, the shorter the fatigue life consequently becomes; (ii) the effect of the loading path complexity, i.e., the greater the loading complexity, the greater the additional hardening, the shorter the fatigue life consequently becomes.

In the light of the results given above, it is obvious that the developed model is able to reproduce the low-cycle fatigue behavior of this alloy under complex cyclic loading paths.

As a final conclusion, this model highlights the advantage to describe qualitatively and quantitatively the simple and complex cyclic damaged behavior of polycrystals notably the effect of the cyclic loading complexity on the fatigue life and on the local heterogeneities.

\section{REFERENCES}

Abdul-Latif, A. (1994). Approches Multi-échelles pour la Description de l'Anélasticité Cyclique avec Endommagement, Ph.D. Thesis, Université de Technologie de Compiègne.

Abdul-Latif, A. (1999). Unilateral Effect in Plastic Fatigue with Micromechanical Approach, Int. J. Damage Mech., 8(4): 316-338.

Abdul-Latif, A. (2004). Pertinence of the Grains Aggregate Type on the Self-consistent Model Response, Int. J. Solids Struct., 41(2): 305-322.

Abdul-Latif, A. and Saanouni, K. (1994). Damaged Anelastic Behavior of FCC Polycrystalline Metals with Micromechanical Approach, Int. J. Damage Mech., 3(3): 237-259.

Abdul-Latif, A. and Saanouni, K. (1996). Micromechanical Modeling of Low Cyclic Fatigue under Complex Loadings - Part II. Applications, Int. J. Plasticity, 12(9): 1123-1149.

Abdul-Latif, A. and Saanouni, K. (1997). Effect of Some Parameters on the Plastic Fatigue Behavior with Micromechanical Approach, Int. J. Damage Mech., 6(4): 433-452.

Abdul-Latif, A., Ferney, V. and Saanouni, K. (1999). Fatigue Damage of Waspaloy under Complex Loading, ASME, J. Eng. Mat. Tech., 121: 278-285.

Abdul-Latif, A., Dingli, J. P. and Saanouni, K. (2002a). Elasto-inelastic Self-consistent Model for Polycrystals, J. Applied Mechanics, 69(3): 309-316.

Abdul-Latif, A., Saanouni, K. and Dingli, J. P. (2002b). Multiscale Modeling for Describing the Multiaxial Low-cycle Fatigue for Polycrystals, In: Ahzi, S., Cherkaoui, M., Khaleel, M.A., Zbib, H.M, Zikry, M.A. and LaMatina, B. (eds), IUTAM Symposium on Multiscale Modeling and Characterization of Elastic-inelastic Behavior of Engineering Materials, Kluwer, The Netherlands, p. 141.

Asaro, R.J. (1983). Crystal Plasticity, J. Appl. Mech., 50: 921. 
Berveiller, M. and Zaoui, A. (1979). An Extension of the Self-consistent Scheme to Plasticity Flowing Polycrystals, J. Mech. Phys. Solids, 26: 325.

Calloch, S. (1997). Essais Triaxiaux Non-proportionnels et Ingénierie des Modèles de Plasticité Cyclique, Ph.D. Thesis, Université Paris VI.

Chadli, M. and Abdul-Latif, A. (2005). Meso-damage Evolution in Polycrystals, ASME, J. Eng. Mat. Tech., 127(2): 214-221.

Cordebois, J.P. and Sidoroff, F. (1979). Damage Induced Elastic Anisotropy, Colloque Euromech, Vol. 115, Villard de Lans, France.

Dingli, J.P., Abdul-Latif, A. and Saanouni, K. (2000). Predictions of the Complex Cyclic Behavior of Polycrystals using a New Self-consistent Modeling, Int. J. Plasticity, 16(3-4): 411-437.

Ferney, V. (1994). Etude de l'Ecrouissage Cyclique sous Sollicitations Complexes, Ph.D. Thesis, Université de Technologie de Compiègne.

Heino, S. and Karlsson, B. (2001). Cyclic Deformation and Fatigue Behaviour of $7 \mathrm{Mo}-0.5 \mathrm{~N}$ Superaustenitic Stainless Steel-slip Characteristics and Development of Dislocation Structures, Acta Mater., 49(2): 353-363.

Hutchinson, J.W. (1976). Bounds and Self-consistent Estimate for Creep of Polycrystalline Materials, Proc. Roy. Soc. London, A348: 101.

Manonukul, A. and Dunne, F.P.E. (2004). High- and Low-cycle Fatigue Crack Initiation using Polycrystal Plasticity, Proc. Roy. Soc., Proceedings: Mathematical, Physical and Engineering Sciences, 460(2047): 1881-1903.

Molinari, A., Canova, G.R. and Ahzi, S. (1987). A Self-consistent Approach of the Large Deformation Viscoplasticity, Acta Metall., 35(12): 2983-2994.

Molinari, A., Ahzi, S. and Kouddane, R. (1997). On the Self-consistent Modeling of Elastoplastic Behavior of Polycrystals, Mech. Mater., 26(1): 43-62.

Nemat-Nasser, S. and Obata, M. (1986). Rate-dependent, Finite Elasto-plastic Deformation of Polycrystals, Proc. Roy. Soc. London, A407: 343.

Pilvin, P. (1990). Approches Multiéchelles pour la Prévision du Comportement Anélastique des Métaux, Ph.D. Thesis, Université Paris VI.

Saanouni, K. and Abdul-Latif, A. (1996). Micromechanical Modeling of Low Cyclic Fatigue under Complex Loadings - Part I. Theoretical Formulation, Int. J. Plasticity, 12(9): 1111-1121.

Saanouni, K., Forster, Ch. and Benhatira, F. (1994). On the Anelastic Flow with Damage, Int. J. Damage Mech., 3: 140.

Sachs, G. (1928). Zur Ableitung einer Fliessbedingung, Z. Ver. Dent. Ing., 72: 734.

Taylor, G.I. (1938). Plastic Strain in Metals, J. Inst. Metals, 62: 307. 